Supporting Information

\title{
Diamond-like carbon thin film electrodes for microfluidic bioelectrochemical sensing platforms
}

\section{Napat Triroj $^{a, *}$, Rattanakorn Saensak ${ }^{a}$, Supanit Porntheeraphat ${ }^{b, c}$, Boonchoat Paosawatyanyong ${ }^{d}$, and Vittaya Amornkitbamrung ${ }^{e}$}

${ }^{a}$ Department of Electrical Engineering, Faculty of Engineering, Khon Kaen University, Khon Kaen 40002, Thailand

${ }^{b}$ Thai Microelectronics Center (TMEC), Chachoengsao 24000, Thailand

${ }^{c}$ National Electronics and Computer Technology Center, Pathum Thani 12120, Thailand

${ }^{d}$ Department of Physics, Faculty of Science, Chulalongkorn University, Bangkok 10330, Thailand

e Department of Physics, Faculty of Science, Khon Kaen University, Khon Kaen 40002, Thailand

* Corresponding author. E-mail: napatr@kku.ac.th 


\section{Detailed analysis of the Raman spectrum}

In general, the Raman spectra of diamond-like carbon films consist of a distinctive broad band of overlapping components. These are designated the D band (around $1350 \mathrm{~cm}^{-1}$ ) and the $\mathrm{G}$ band (around $\left.1580 \mathrm{~cm}^{-1}\right) .{ }^{1}$ The $\mathrm{D}$ and $\mathrm{G}$ bands in the Raman spectrum originate from different vibrational modes. The $\mathrm{D}$ band originates from the $\mathrm{A}_{1 \mathrm{~g}}$ mode of diamond-like carbon with an $\mathrm{sp}^{3}$ electronic configuration, while $\mathrm{G}$ band originates from the $\mathrm{E}_{2 \mathrm{~g}}$ vibration of carbon with an $\mathrm{sp}^{2}$ electronic configuration. ${ }^{2}$ As observed from the Raman spectrum, the $\mathrm{G}$ peak was positioned at a slightly higher wave number. The high wave number for the G-band peak has been attributed to a high content of $\mathrm{sp}^{2}$ bonding state carbon, ${ }^{3-5}$ which suggests a low $\mathrm{sp}^{3}$ content in the films. ${ }^{6}$ This could have been derived from the presence of olefinic $\mathrm{sp}^{2}$ groups that contribute to higher vibrational frequencies than those of graphite. ${ }^{7}$ For hydrogenated amorphous carbon, hydrogen atoms alter the carbon network by saturating $\mathrm{C}=\mathrm{C}$ groups into $\mathrm{sp}^{3}$ bonded $\mathrm{CH}-\mathrm{CH}$ groups. ${ }^{2}$ The dependence of the $\mathrm{G}$ peak position on the $\mathrm{H}$ content for a-C:H films deposited by methane suggests that the low hydrogen content in the films gives rise to a $G$ peak shift toward higher wavenumbers. ${ }^{8}$ In other words, the low hydrogen content in the films implies a high fraction of $\mathrm{sp}^{2}$ hybridization states. The dispersion in the Raman $\mathrm{G}$ peak position in a-C:H films also provides an insight to estimate the ratio of $\mathrm{sp}^{3}$ and $\mathrm{sp}^{2}$ fractions in carbon materials. ${ }^{9}$ The quantitative analysis suggested that the $\mathrm{sp}^{3}$ content in the films was approximately $22 \%$. The relatively low $\mathrm{sp}^{3}$ content or high $\mathrm{sp}^{2}$ $\mathrm{C}$ fraction is expected due to the selected gas mixture ratio and the magnitude of the negative selfbias voltage $(-440 \mathrm{~V})$ used in the deposition process. ${ }^{10}$ 


\section{Optical band gap estimation}

According to Beer-Lambert's law, the absorption coefficient, $\alpha$, can be calculated using equation (S-1):

$$
\alpha=\frac{1}{d} \ln \left(\frac{1}{T}\right)=\frac{A}{d}
$$

where $d$ is the film thickness, $T$ is the transmittance, and $A$ is the absorbance. The inset in Figure S-1 shows the recorded absorbance of the prepared DLC films. Most frequently in amorphous materials, the optical band gap $E_{g}$ is obtained using the Tauc relation given by equation (S-2): ${ }^{11}$

$$
(\alpha h v)^{1 / 2}=A\left(h v-E_{g}\right)
$$

where $A$ is a constant and $h v$ is the incident photon energy. The optical band gap can be estimated by extrapolating the linear portion of the $(\alpha h v)^{1 / 2}$ vs. $h v$ plot to the intercept of the $h v$ axis where $(\alpha h v)^{1 / 2}=0$. The optical band gap of the DLC films was found to be approximately 1.67 $\mathrm{eV}$ as shown in Figure $\mathrm{S}-1$, represented by the dashed line. Typical hydrogenated amorphous carbon films were reported to have a maximum optical band gap of $4 \mathrm{eV}$ in the presence of a high $\mathrm{H}$ content DLC and a minimum optical band gap of $0.5 \mathrm{eV}$ for a very high $\mathrm{sp}^{2}$ content DLC. ${ }^{12}$ When the optical band gap falls within the range of 1-1.8 eV, the films are considered to have a diamond-like character (a-C:H hard) with an intermediate $\mathrm{H}$ content. ${ }^{1,2}$ Since the Raman results 
suggested a high wave number of the G peak position, an optical band gap with this value would be possible. ${ }^{8}$ As the optical band gap varies inversely with the size of the graphitic cluster in the films, smaller optical band gaps correspond to larger clusters with a relatively high $\mathrm{sp}^{2}$ content. $^{13}$

It is well established that the optical band gap of DLC films is dependent upon the $\pi$ states of $\mathrm{sp}^{2}$ sites. ${ }^{13,14}$ These localized states form band edges and allow hopping transport of charge carriers. Their electrical conductivity is therefore expected to increase with the concentration of localized $\pi$ states. The increase of these localized states at the band edges narrows the optical band gap. To control the number of $\mathrm{sp}^{2}$ sites, the negative self-bias voltage of the deposition system can be adjusted. ${ }^{10}$ The relatively high negative bias $(-440 \mathrm{~V})$ used in our system was aimed to increase the $\mathrm{sp}^{2}$ fraction in the films.

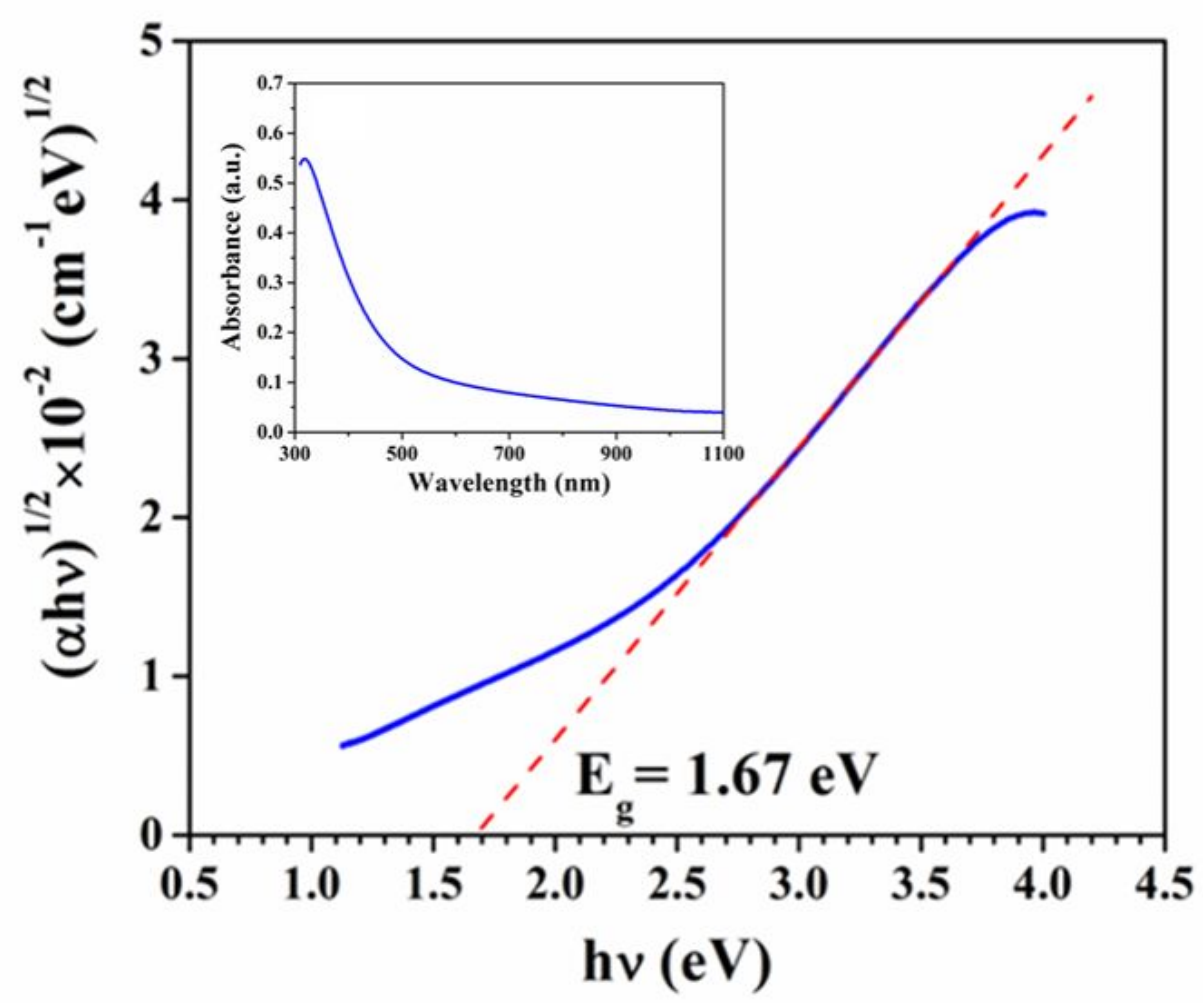

Figure S-1. The Tauc plot of the DLC films. (Inset) The UV-Visible absorption spectrum. 


\section{Electrode calibration in microchannels}

The electrochemical characteristics of DLC electrode in a microchannel can be obtained from a voltammetric study performed with a standard redox system such as $\mathrm{Fe}(\mathrm{CN})_{6}^{3-/ 4-}$. Figure $\mathrm{S}$ 2a shows cyclic voltammograms of $10 \mathrm{mM} \mathrm{K}_{3} \mathrm{Fe}(\mathrm{CN})_{6}$ in $1 \mathrm{M} \mathrm{KNO}_{3}$ at various scan rates. The inset shows a plot of cathodic and anodic peak currents $\left(I_{\mathrm{p}}\right)$ versus square root of the scan rates ( $\left.v^{1 / 2}\right)$. The peak current ratios $\left(\left|I_{\mathrm{pa}}\right| /\left|I_{\mathrm{pc}}\right|\right)$ are close to unity, and $I_{\mathrm{p}}$ follows a linear relationship with $v^{1 / 2}$. With increasing scan rates, the peak potential separation $\left(\Delta E_{\mathrm{p}}\right)$ was found to increase from 224 to $327 \mathrm{mV}$. This is due to the introduction of kinetic limitations due to the shorter time scale of the experiments. ${ }^{15}$ At faster scan rates, an equilibrium condition is not reached and the rate of the electrode reaction is limited by the kinetics of the electron transfer at the electrode/solution interface. The shift of $E_{\mathrm{p}}$ to more negative potentials for reduction and to more positive potentials for oxidation refers to the degree of irreversibility of the electrode process. In this case, the theory from Nicholson and Shain was used to find the standard potential $\left(E^{0}\right)$ and hence the formal potential $\left(E^{0 \prime}\right)$ of the redox species, assuming that the activities of both redox species are equal to one and the transfer coefficient $(\beta)$ is $0.5 .{ }^{16}$ Hence, the average $E^{0 \prime}(0.144 \mathrm{~V}$ vs. Ag) can be obtained from the midpoint of the cathodic peak potentials $\left(E_{\mathrm{pc}}\right)$ and the anodic peak potentials ( $\left.E_{\mathrm{pa}}\right)$. The resulting formal redox potential was $0.244 \mathrm{~V}$, obtained by converting to the SCE scale, which is comparable to the results found in the literature. ${ }^{17}$ Thus, the results obtained from voltammetric analysis indicate that the DLC electrode responses to a standard redox species measured in a microchannel are subjected to quasi-reversible charge transfer under linear diffusion. $^{18}$

The heterogeneous electron transfer rate constant $\left(k_{0}\right)$ between the electrode and solution is a parameter that determines the reaction rate at the electrode surface. For quasi-reversible 
diffusion-controlled processes, the $k_{0}$ parameter can be extracted from $\Delta E_{\mathrm{p}}$ values. Using the Nicholson method, ${ }^{19}$ the kinetic parameter, $\psi$, is defined as shown in equation (S-3):

$$
\psi=k^{0}[\pi D n v F /(R T)]^{-1 / 2}
$$

where $D$ is the diffusion coefficient, $n$ is the number of electrons transferred in the electrode reaction, $F$ is the Faraday constant, $R$ is the gas constant, and $T$ is the absolute temperature. The diffusion coefficient of ferricyanide at $25^{\circ} \mathrm{C}$ is $7.26 \times 10^{-6} \mathrm{~cm}^{2} / \mathrm{s} .{ }^{20}$ When $n \Delta E_{\mathrm{p}}$ values exceed 200 $\mathrm{mV}, \psi$ is related to $n \Delta E_{\mathrm{p}}$ as follows: ${ }^{21-23}$

$$
\psi=2.18(\beta / \pi)^{1 / 2} \exp \left[-\left(\beta^{2} F / R T\right) n \Delta E_{\mathrm{p}}\right]
$$

With the combined use of equations (S-3) and (S-4), $k^{0}$ was evaluated from the slope of the plot of $\psi$ vs. $[\pi D n F /(R T)]^{-1 / 2} v^{-1 / 2}$ as shown in Fig. S2b. By taking $\beta=0.5$ and $n=1, k^{0}$ is $6.2 \times 10^{-4} \mathrm{~cm} / \mathrm{s}$, indicating a quasi-reversible behavior. It is established that the electron transfer rate constant is strongly influenced by several variables including the electronic properties and the surface chemistry of the electrode. The electrode kinetics of $\mathrm{Fe}(\mathrm{CN}) 6^{3-/ 4-}$ is sensitive to the electronic properties and surface chemistry properties (i.e., surface terminations and surface cleanliness) of an electrode. ${ }^{24}$ In the case of a boron-doped diamond (BDD) electrode, $\Delta E_{\mathrm{p}}$ of $\mathrm{Fe}(\mathrm{CN})_{6}^{3-4-}$ is very sensitive to the surface termination, as the smallest $\Delta E_{\mathrm{p}}$ was observed at a hydrogen-terminated surface. Larger $\Delta E_{\mathrm{p}}$ values were observed with a BDD electrode containing 
oxygen functionalities on its surface. ${ }^{25}$ The electron transfer kinetics on the BDD electrode were inhibited due to the electrostatic repulsive forces between the negative surface charge density due to the oxygen termination on the electrode and negative charges on $\mathrm{Fe}(\mathrm{CN})_{6}^{3-14}$. A similar observation of a decrease of $k^{0}$ in a PECVD DLC that contained surface functional groups with $\mathrm{C}=\mathrm{O}$ bonds created by $\mathrm{O}_{2}$ plasma treatment was reported. ${ }^{26}$ The analysis the electrode reaction rate therefore confirms the presence of oxygen species at the electrode surface.
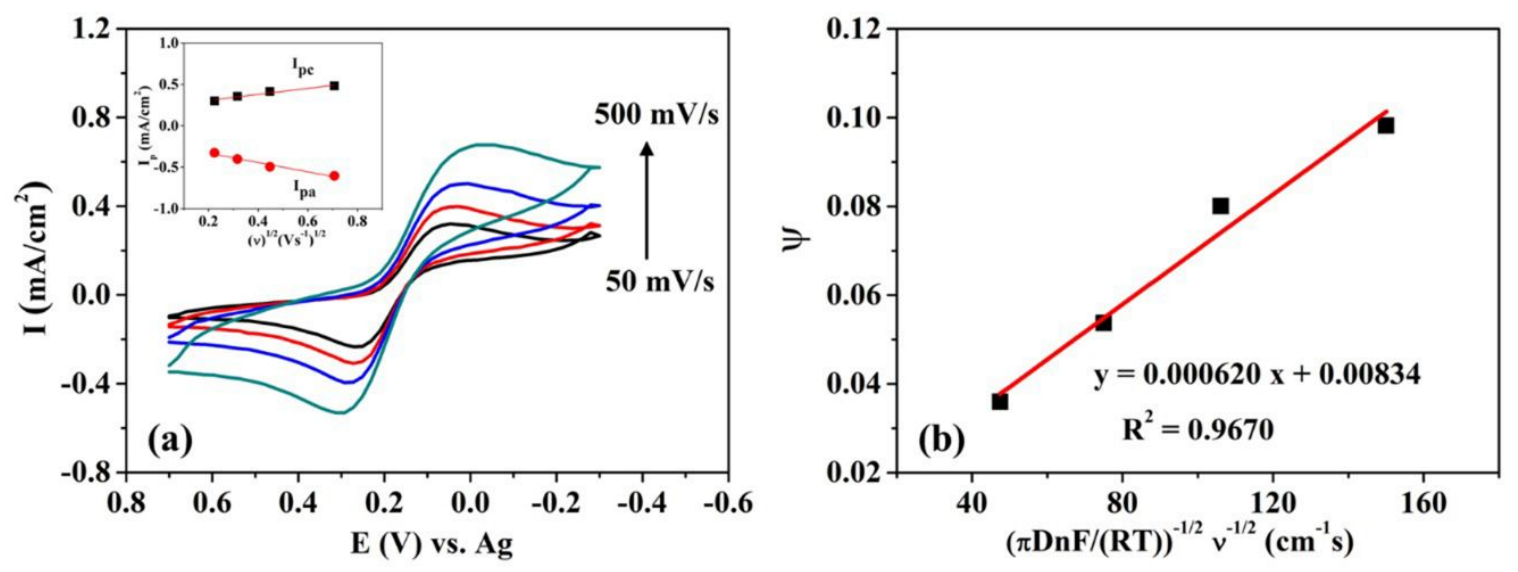

Figure S-2. (a) Cyclic voltammograms of a DLC electrode in a microchannel measured in a $10 \mathrm{mM} \mathrm{K}_{3} \mathrm{Fe}(\mathrm{CN})_{6} / 1 \mathrm{M} \mathrm{KNO}_{3}$ solution at various scan rates: 50, 100,200 , and $500 \mathrm{mV} / \mathrm{s}$. (Inset) The inset plot showing cathodic and anodic peak currents $\left(I_{\mathrm{p}}\right)$ versus the square root of the scan rates $\left(v^{1 / 2}\right)$. (b) Plot of $\psi$ vs. $[\pi D n F /(R T)]^{-1 / 2} v^{-1 / 2}$ computed from equations (S-3) and (S-4).

\section{References}

(1) Robertson, J. Mater. Sci. Eng. R Reports 2002, 37 (4-6), 129-281. 
(2) Ferrari, A. C.; Robertson, J. Phys. Rev. B 2000, 61, 14095-14107.

(3) Knight, D. S.; White, W. B. J. Mater. Res. 1989, 4, 385-393.

(4) Diamant, R.; Jimenez, E.; Haro-Poniatowski, E.; Ponce, L.; Fernandez-Guasti, M.;

Alonso, J. C. Diam. Relat. Mater. 1999, 8 (7), 1277-1284.

(5) Nurk, G.; Jaanus, A.; Ae, E.; Jaaniso, R.; Lust, E. J. Solid State Electrochem. 2003, 7, $421-434$.

(6) Ferrari, A. C.; Libassi, A.; Tanner, B. K.; Stolojan, V.; Yuan, J.; Brown, L. M.; Rodil, S.

E.; Kleinsorge, B.; Robertson, J. Phys. Rev. B 2000, 62 (16), 11089-11103.

(7) Irmer, G.; Dorner-Reisel, A. Adv. Eng. Mater. 2005, 7 (8), 694-705.

(8) Tamor, M. A.; Vassell, W. C. J. Appl. Phys. 1994, 76 (6), 3823-3830.

(9) Singha, A.; Ghosh, A.; Roy, A.; Ray, N. R. J. Appl. Phys. 2006, 100 (4), 044910.

(10) Staryga, E.; Bąk, G. W.; Dłużniewski, M. Vacuum 2004, 74, 325-330.

(11) Tauc, J.; Grigorovici, R.; Vancu, A. Phys. status solidi 1966, 15 (2), 627-637.

(12) Grill, A. Thin Solid Films 1999, 355-356, 189-193.

(13) Robertson, J. Semicond. Sci. Technol. 2003, 18 (3), S12-S19.

(14) Bredas, J. L.; Street, G. B. J. Phys. C Solid State Phys. 1985, 18 (21), L651-L655.

(15) C.M.A. Brett and A.M.O. Brett. Electroanalysis, 1st ed.; Oxford University Press, 2005.

(16) Nicholson, R. S.; Shain, I. Anal. Chem. 1964, 36, 706-723. 
(17) Kissinger, P. T.; Heineman, W. R. J. Chem. Educ. 1983, 60, 702-706.

(18) A.J. Bard and L.R. Faulkner. Electrochemical Methods: Fundamentals and Applications; New York: Wiley, 1980.

(19) Nicholson, R. S. Anal. Chem. 1965, 37, 1351-1355.

(20) Konopka, S. J.; McDuffie, B. Anal. Chem. 1970, 42 (14), 1741-1746.

(21) Klingler, R. J.; Kochi, J. K. J. Phys. Chem 1981, 85, 1731-1741.

(22) Lavagnini, I.; Antiochia, R.; Magno, F. Electroanalysis 2004, 16 (6), 505-506.

(23) Silva, T. A.; Zanin, H.; May, P. W.; Corat, E. J.; Fatibello-Filho, O. ACS Appl. Mater. Interfaces 2014, 6, 21086-21092.

(24) Zeng, A.; Neto, V. F.; Gracio, J. J.; Fan, Q. H. Diam. Relat. Mater. 2014, 43, 12-22.

(25) Yagi, I.; Notsu, H.; Kondo, T.; Tryk, D. A.; Fujishima, A. J. Electroanal. Chem. 1999, $473,173-178$.

(26) Tanaka, Y.; Furuta, M.; Kuriyama, K.; Kuwabara, R.; Katsuki, Y.; Kondo, T.; Fujishima, A.; Honda, K. Electrochim. Acta 2010, 56, 1172-1181.

(1) Robertson, J. Mater. Sci. Eng. R Reports 2002, 37 (4-6), 129-281.

(2) Ferrari, A. C.; Robertson, J. Phys. Rev. B 2000, 61, 14095-14107.

(3) Knight, D. S.; White, W. B. J. Mater. Res. 1989, 4, 385-393.

(4) Diamant, R.; Jimenez, E.; Haro-Poniatowski, E.; Ponce, L.; Fernandez-Guasti, M.; Alonso, J. C. Diam. Relat. Mater. 1999, 8 (7), 1277-1284. 
(5) Nurk, G.; Jaanus, A.; Ae, E.; Jaaniso, R.; Lust, E. J. Solid State Electrochem. 2003, 7, 421-434.

(6) Ferrari, A. C.; Libassi, A.; Tanner, B. K.; Stolojan, V.; Yuan, J.; Brown, L. M.; Rodil, S. E.; Kleinsorge, B.; Robertson, J. Phys. Rev. B 2000, 62 (16), 11089-11103.

(7) Irmer, G.; Dorner-Reisel, A. Adv. Eng. Mater. 2005, 7 (8), 694-705.

(8) Tamor, M. A.; Vassell, W. C. J. Appl. Phys. 1994, 76 (6), 3823-3830.

(9) Singha, A.; Ghosh, A.; Roy, A.; Ray, N. R. J. Appl. Phys. 2006, 100 (4), 044910.

(10) Staryga, E.; Bąk, G. W.; Dłużniewski, M. Vacuum 2004, 74, 325-330.

(11) Tauc, J.; Grigorovici, R.; Vancu, A. Phys. status solidi 1966, 15 (2), 627-637.

(12) Grill, A. Thin Solid Films 1999, 355-356, 189-193.

(13) Robertson, J. Semicond. Sci. Technol. 2003, 18 (3), S12-S19.

(14) Bredas, J. L.; Street, G. B. J. Phys. C Solid State Phys. 1985, 18 (21), L651-L655.

(15) C.M.A. Brett and A.M.O. Brett. Electroanalysis, 1st ed.; Oxford University Press, 2005.

(16) Nicholson, R. S.; Shain, I. Anal. Chem. 1964, 36, 706-723.

(17) Kissinger, P. T.; Heineman, W. R. J. Chem. Educ. 1983, 60, 702-706.

(18) A.J. Bard and L.R. Faulkner. Electrochemical Methods: Fundamentals and Applications; New York: Wiley, 1980.

(19) Nicholson, R. S. Anal. Chem. 1965, 37, 1351-1355. 
(20) Konopka, S. J.; McDuffie, B. Anal. Chem. 1970, 42 (14), 1741-1746.

(21) Klingler, R. J.; Kochi, J. K. J. Phys. Chem 1981, 85, 1731-1741.

(22) Lavagnini, I.; Antiochia, R.; Magno, F. Electroanalysis 2004, 16 (6), 505-506.

(23) Silva, T. A.; Zanin, H.; May, P. W.; Corat, E. J.; Fatibello-Filho, O. ACS Appl. Mater. Interfaces 2014, 6, 21086-21092.

(24) Zeng, A.; Neto, V. F.; Gracio, J. J.; Fan, Q. H. Diam. Relat. Mater. 2014, 43, 12-22.

(25) Yagi, I.; Notsu, H.; Kondo, T.; Tryk, D. A.; Fujishima, A. J. Electroanal. Chem. 1999, $473,173-178$.

(26) Tanaka, Y.; Furuta, M.; Kuriyama, K.; Kuwabara, R.; Katsuki, Y.; Kondo, T.; Fujishima, A.; Honda, K. Electrochim. Acta 2010, 56, 1172-1181. 